\title{
Erratum to: Not black or white, but brown: A common finding explained!
}

\author{
Matthew Jones, $M D,{ }^{a}$ Yasser Rodriguez, MD, MBA, ${ }^{\text {a }}$ Sandeep Patel, $M D,{ }^{a}$ \\ Elliott Gozansky, MD, PhD, ${ }^{b}$ and Prem Soman, MD, PhD, FRCP (UK), FACC \\ a Division of Cardiology, University of Pittsburgh Medical Center, Pittsburgh, PA \\ ${ }^{b}$ Department of Radiology, University of Pittsburgh Medical Center, Pittsburgh, PA
}

doi:10.1007/s12350-016-0437-z

ERRATUM TO: J NUCL CARDIOL

DOI 10.1007/S12350-016-

0397-3

The family name of the second author is misspelled in the published article. "Rodrigues", should be "Rodriguez" as shown in the author list of this erratum.

The online version of the original article can be found under doi:10.1007/s12350-016-0397-3.

Reprint requests: Prem Soman, MD, PhD, FRCP (UK), FACC,

Division of Cardiology, University of Pittsburgh Medical Center,

A-429 Scaife Hall, 200 Lothrop Street, Pittsburgh, PA 15213;

premsoman@usa.net,somanp@upmc.edu

J Nucl Cardiol 2016;23:587.

1071-3581/\$34.00

Copyright (C) 2016 American Society of Nuclear Cardiology. 